\title{
GeoHazards: A New Interdisciplinary Journal Devoted to the Study of Geomorphological Hazards
}

\author{
Tiago Miguel Ferreira ${ }^{1, *(1)}$ and Zhong $\mathrm{Lu}^{2}$ (D) \\ 1 Editor-in-Chief of GeoHazards, ISISE, Department of Civil Engineering, University of Minho, \\ 4800-058 Guimarães, Portugal \\ 2 Editor-in-Chief of GeoHazards, Roy M. Huffington Department of Earth Sciences, \\ Southern Methodist University, Dallas, TX 75275-0395, USA; zhonglu@smu.edu \\ * Correspondence: tmferreira@civil.uminho.pt; Tel.: +351-253-510-200
}

Received: 23 May 2018; Accepted: 23 May 2018; Published: 2 June 2018

The name GeoHazards comes from the word "geomorphological", which refers to the study of the physical features of the surface of the earth and their relation to its geological structures, and the word "hazard", meaning an agent which has the potential to cause harm to a vulnerable target. Despite the development of a considerable amount of work concerning hazards from various geomorphological approaches, relatively limited definitions of geomorphological hazards have been established. While for some authors, geomorphological hazards can be defined as the events or processes, natural or human-induced, that may be potentially detrimental to humans and their activities, for others, a geomorphological hazard can be understood as the probability that a certain phenomenon of a given magnitude may occur in a certain territory in a given period of time. Under this conceptual umbrella, progresses in geomorphological hazards have been linked to the rising interest in environmental issues, particularly to the global understanding of climate and land-use change, vulnerability, hazard assessment, risk management, and disaster prevention.

In recent years, research on geomorphological hazards has moved into a new era driven by the emergence of new technologies and techniques with great potential to be used in risk management and mitigation, risk vulnerability, preparedness, and early warning. Nevertheless, in spite of these advances, the effects of natural and man-made hazards are inexorably increasing and have to be seen in the context of an increasingly complex, interdependent, and populated world. In order to tackle this global issue, it is fundamental to engage in and develop fundamental and applied research that, on a multidisciplinary basis, can lead to the development and implementation of more efficient risk mitigation practices. GeoHazards seeks to contribute to this goal, by constituting itself as an open access forum where scientists, engineers, civil defense officers, administrators, policy-makers, and others can exchange, interact, and communicate their studies both to researchers in other geomorphological, hazards-related disciplines and to interested nonspecialists.

The journal is devoted to original interdisciplinary research across the whole spectrum of geomorphological hazards: endogenous hazards, such as earthquakes, volcanoes, and tsunamis; exogenous hazards, such as climatological hazards (e.g., sea level rise, droughts, extreme heat, desertification, coastal erosion, and soil erosion); meteorological hazards (e.g., wildfires, hurricanes, cyclones and tornados, monsoons, thunderstorms, extreme temperatures, severe winter storms, windstorms, and sandstorms); hydrological hazards (e.g., storm surges, river floods, and flash floods); mass-movement hazards (e.g., landslides, rock falls, debris flows, mudflows, avalanches, land subsidence, sinkholes, and soil expansion phenomena); anthropogenic hazards, i.e., those caused directly or indirectly by human action or inaction (e.g., terrorism, explosions, urban fires, air pollution and atmospheric dispersion, industrial accidents, induced earthquakes); and technological accidents triggered by natural disasters. 
GeoHazards will publish reviews, research articles, communications, technical notes, and essays so that the scientific and technical community may use the lessons learnt for risk management and mitigation. In this sense, particularly welcome are contributions dealing with the development, validation, and practical implementation of innovative techniques, methods, and tools for the assessment, analysis, and mitigation of these hazards. The analysis of the interactions between geomorphological hazards and society, including risk governance, disaster response and risk perception, communication, and education are also within the scope of GeoHazards.

The international and interdisciplinary character of the journal has been ensured by the selection of a remarkable group of eminent geomorphological hazard scientists from around the world to serve as members of the Editorial Board. These members will provide advice, guidance, and assistance on a wide range of issues, as well as form more immediate points of contact for researchers in their countries.

On behalf of GeoHazards' Editorial Board, we welcome you to this new forum. To encourage authors worldwide to adopt the open access model, the publication charges will be fully waived for papers submitted to the journal in 2018 and 2019. With your support, we hope that it will soon begin to contribute effectively towards further developments in this important field. 